\title{
COMPARISON OF BITE FORCE RECOVERY FOLLOWING TREATMENT OF MANDIBULAR ANGLE FRACTURE USING ONE AND TWO MINIPLATES
}

\author{
Ahmed A. Abo Mustafa' ${ }^{1} \mathrm{BDS}$, Moustafa M. El Dibany'2 PhD, Mohamed M. Shokry ${ }^{3} \mathrm{PhD}$, \\ Lydia N. Foad ${ }^{3} \mathrm{PhD}$
}

\begin{abstract} one monocortical miniplate and two monocortical miniplates fixation. for 6 weeks and at 3 months postoperatively. at week 6 and 12 in the left molar region. miniplate osteosynthesis had proven to be a suitable method for treating mandibular angle fractures.

KEYWORDS: mandible fracture, angle, miniplates, bite force.

1- B.D.S. Faculty of Dentistry, Misr University for Science and Technology (MUST), Cairo, Egypt.

2- Professor of Oral and Maxillofacial Surgery, Faculty of Dentistry Alexandria University, Alexandria, Egypt

3- Lecturer of Oral and Maxillofacial Surgery, Faculty of Dentistry Alexandria University, Alexandria, Egypt
\end{abstract}

INTRODUCTION: Rigid internal fixation using compression and non-compression plating systems has gained widespread popularity. The maximal bite force is the effort exerted between the maxillary and mandibular teeth when the mandible is elevated by the masticatory muscles. OBJECTIVES: The Present study was conducted to compare the bite force recovery in patients with mandibular angle fractures treated by

MATERIALS AND METHODS: Bite force (in $\mathrm{kg}$ ) was recorded in fourteen patients with mandibular angle fractures. Comparative evaluation of bite force generated was performed between seven cases treated with one monocortical miniplate and seven cases treated with two monocortical miniplates. Bite force generated by patients with mandibular angle fractures was recorded in incisor, premolar and molar regions preoperatively. The fracture fragments were fixed using the above fixation techniques. Then same recordings were undertaken weekly

RESULTS: Bite force increased gradually in both groups in the anterior region, premolar region (right and left) and molar region (right and left) during the follow up period except a drop in group I during the $5^{\text {th }}$ week in the right molar region. A statistically significant difference was found between the change in bite force from the previous follow-up visit in groups 1 and 2. This was shown from week 1 to week 4 in the incisor region, at week 1 in the right premolar region, at week 3 in the left premolar region, at week 5, 6 and 12 in the right molar region and

CONCLUSIONS: No significant difference between the uses of either one or two miniplates osteosynthesis in fixation of angle fractures. The

\section{INTRODUCTION}

Mandibular fractures are the second, most-frequent facial injuries treated at a trauma center. According to several studies, they account for $36 \%$ to $70 \%$ of all facial fractures $(1-4)$.

Angle fractures are often unfavorable because of the actions of the masseter, temporalis, and medial pterygoid muscles, which distract the proximal segment superomedially (5).

Miniplates osteosynthesis is accomplished by placement of a plate along the so-called ideal line of osteosynthesis, thereby counteracting distraction forces that occur along the fracture line during mandibular function (6).

Forces applied by the masticatory muscles in dental occlusion (i.e., bite force) following treatment of mandibular fractures have received little attention. The bite force is one of the components of the chewing function. It increases with age from childhood, stays fairly constant from 20 to 40 years of age and then declines. The maximum voluntary bite force measurement in healthy male is of the order of 50 pounds in American population $(7,8)$. The maximal bite force is the effort exerted between the maxillary and mandibular teeth when the mandible is elevated by the masticatory muscles (9).

Someone who generates higher force during mastication might have a better masticatory performance. Someone with carious, painful teeth will unconsciously avoid those teeth during mastication, reducing the performance of mastication. If there is a correlation between masticatory performance and bite forces, then bite forces could be used as a clinical indicator of masticatory performance (10).

Fractures of the mandible not only cause a change in the skeletal architecture but also lead to changes in the other components of the masticatory apparatus in the form of masticatory muscle tear or injury and neurovascular injuries. Surgical treatment of mandibular fractures aims at restoration of skeletal form of the mandible with a hope that normal function and esthetics would be restored (11).

Thus the aim of this study was to compare the bite force recovery in patients with mandibular angle fractures treated by one monocortical miniplate and two monocortical miniplates fixation.

\section{MATERIALS AND METHODS \\ Study design and setting}

This study was conducted as a randomized controlled clinical trial, in which fourteen patients were selected from the Outpatient clinic and Emergency Ward of the Oral and Maxillofacial Surgery Department, Faculty of Dentistry, Alexandria University, suffering from mandibular angle fracture.

An informed consent was taken and signed by all the participants before performing any surgery.

An ethical approval has been taken from the ethical committee in Alexandria University. 


\section{Patients' selection}

\section{Inclusion criteria}

Mandibular Angle fractures, Minimal dental restorations and Adult patients.

\section{Exclusion criteria}

Patients exhibiting Myofacial pain disorders, Patients with Dentofacial deformities, Patients who have Nurosensory deficiency, Patients presenting with Condylar Fractures, Comminuted fractures.

\section{Patient's categorization}

After the sample was selected conveniently, it was allocated randomly into two groups according to the number of plates used; each group consisted of seven patients.

Group I: Seven patients with fracture angle of the mandible were treated by open reduction and one miniplate fixation without intermaxillary fixation. Group II: Seven patients with fracture angle of the mandible were treated by open reduction and two miniplates fixation without intermaxillary fixation.

\section{I) Materials}

Titanium Mini Plates (Fig. 1), Mini screws (9-11 mm), $1.5 \mathrm{~mm}$ drilling pit (Jeli Medical Corporation Company, Guro$\mathrm{Ku}$,Seoul,Korea)

Bite force sheet (Pressurex ${ }^{\circledR}$, Sensor Products INC, New Jersey, USA.) for recording the recovery of the bite force. (Fig 2) Pressure Indicating Film, which is unique and easy to use. It reveals the distribution and magnitude of the force between any two contacting and mating teeth.

It is extremely thin (4-8 mil), thus it enables it to conform to curved surfaces easily. It is ideal for invasive intolerant environments and tight spaces not accessible to conventional electronic transducers.

Pressure indicating film is a Mylar based film that contains a layer of tiny microcapsules. The application of force upon the film causes the microcapsules to rupture, producing an instantaneous and permanent high resolution "topographical" image of pressure variation across the contact area.

The Pressure Indicating Films used in measuring the bite force is the two-sheet type which is used to measure force range from $2 \mathrm{~kg}$ to $100 \mathrm{~kg}$. It is composed of two polyesterbases. One is coated with a layer of micro-encapsulated color forming material and the other is a layer of the color-developing material.

It is supplied in 3 categories: Ultra low $(2-6 \mathrm{~kg} / \mathrm{cm} 2)$, Super low $(5-25 \mathrm{~kg} / \mathrm{cm} 2)$, Low $(25-100 \mathrm{~kg} / \mathrm{cm} 2)$.

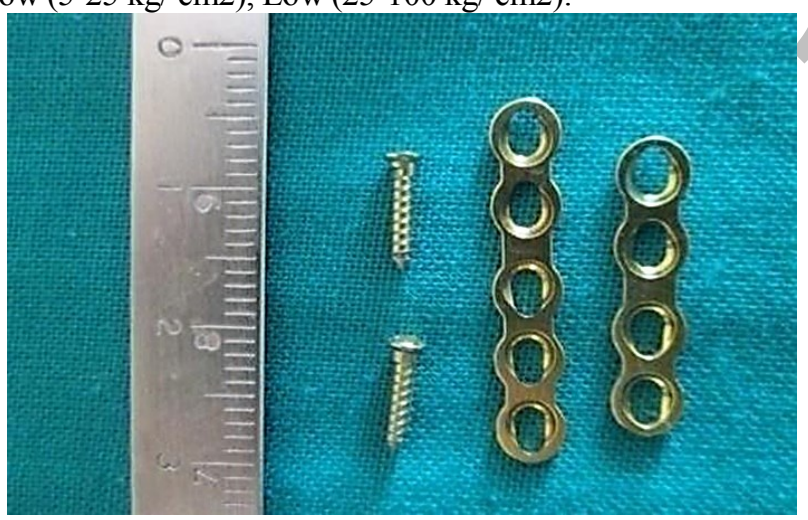

Figure (1): Titanium Miniplates and Mini screws.

\section{II) Method}

\section{I.Preoperative phase}

Pre-operative evaluation was performed for every patient through proper history taking and through clinical and radiographic examination as follows:
1. History: Detailed preoperative data were collected from all the patients presented with mandibular fractures including name, age, gender, occupation, address, data and time of injury, etiology of the injury, immediate measures and any relevant medical or dental history.

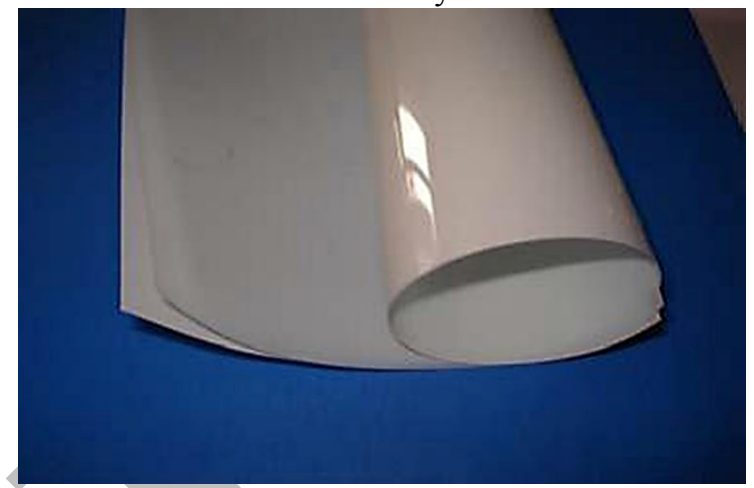

Figure (2): Bite force sheet.

2. Clinical examination: General examination was achieved to evaluate injuries elsewhere in the body. Local examination for the fractured mandible was preformed both extraorally and intraorally.

A- Extraoral Examination was carried out by: Inspection: To record swelling, ecchymosis, obvious deformity of the bony contour, deviation during opening and closing, abnormal movement of the jaw, presence of open bite. Swelling and ecchymosis indicate the site of expected mandibular fractures. Palpation: Both sides of the lower border were palpated to detect the site of tenderness, step deformity and bony crepitus. Also the presence of numbness over the distribution of the inferior alveolar nerve of the affected side was recorded.

B- Intraoral Examination was carried out by: Inspection: to detect the presence of ecchymosis and fracture haematoma in the buccal and lingual sulci, step defects in the occlusal plane or any occlusal abnormalities and soft tissue laceration. Palpation: of the buccal and lingual sulci to detect areas of tenderness and alteration of bony contour. Each tooth was examined for mobility across the site of the fracture. Palpation of the lips and cheeks whenever injured for the suspected presence of a tooth or part of a tooth or any foreign body in the soft tissues.

C- Radiographic Examination: Standard orthopantomograms were performed for all the cases to determine the degree and direction of the displacement of the fractured segment and locate the fracture line.

\section{Pre-operative preparation}

All patients were hospitalized and scheduled for operation. They were prepared intraorally and extraorally by: Shaving the surgical site, suturing any of soft tissue laceration, scaling of the teeth was done if needed.

\section{III.Operative Phase}

All patients were operated under general anesthesia in the Department of Oral and Maxillofacial Surgery, Faculty of Dentistry, Alexandria University.

The following procedures were done for each group:

Group I: Intermaxillary fixation was secured using upper and lower arch bars or eyelet wires according to the number of teeth present, surgical exposure of the fracture site was accomplished through intra oral incision, Adaptation and placement of one miniplate on the superior aspect of the mandible extending onto the broad surface of external 
oblique ridge with 5 holes fixed with 2 screws before fracture line \& 2 screws after fracture line. (Fig 3)

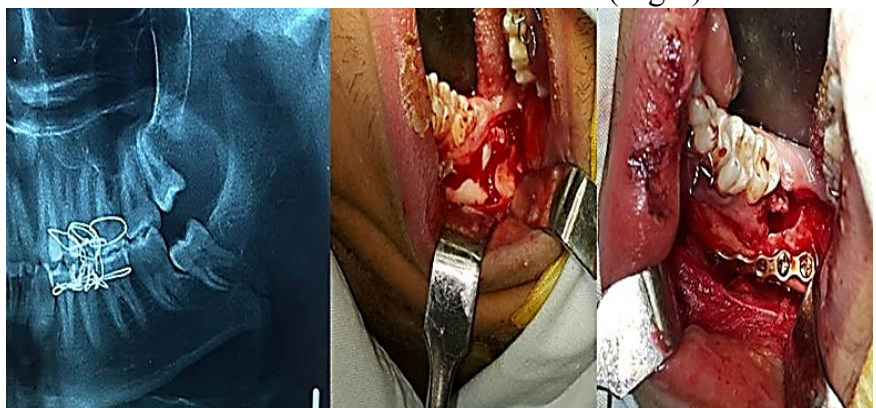

Figure (3): A-Orthopantomogram showing fracture angle, Bexposure of fracture site \& reduction of the segment, C-one miniplate fixation.

Group II: Similar to group I except, surgical exposure of the fracture site was accomplished through extra oral incision, marking the Incision; the incision is 1.5 to $2 \mathrm{~cm}$ inferior to the lower border of the mandible, skin incision, the initial incision was carried through skin and subcutaneous tissues to the level of the platysma muscle; the skin was undermined with scissor dissection in all directions to facilitate closure. The superior portion of the incision is undermined approximately $1 \mathrm{~cm}$; the inferior portion is undermined approximately $2 \mathrm{~cm}$ or more, incision of the platysma muscle was then performed, dissection to the pterygomasseteric muscular sling was done, division of the pterygomasseteric sling and submasseteric dissection, the fracture segments were exposed, reduced and fixed temporarily into perfect anatomic position, adaptation and placement of two miniplates; one on the superior aspect of the mandible extending onto the broad surface of external oblique ridge and other on the lateral aspect of the angle at the inferior border was done, the incision was then closed in layers, after the procedures were complete, intermaxillary fixation was removed.(Fig 4)

For both groups all patients received postoperative Antibiotics and nonsteroidal Anti-inflammatory drug medication twice daily for 7days (Cataflam $50 \mathrm{mg}$ tablets, Novartis pharma AG, Basle, Switzerland, Augmentin 1 gm tablet, smithKline Beecham pharmaceutical Co., England). Chlorhexidine mouthrinse $(0.12 \%)$ was used postoperatively for 7days (Hexitol mouth wash, the Arab drug company for pharmaceutical \& chemical industries. Cairo, A.R.E).

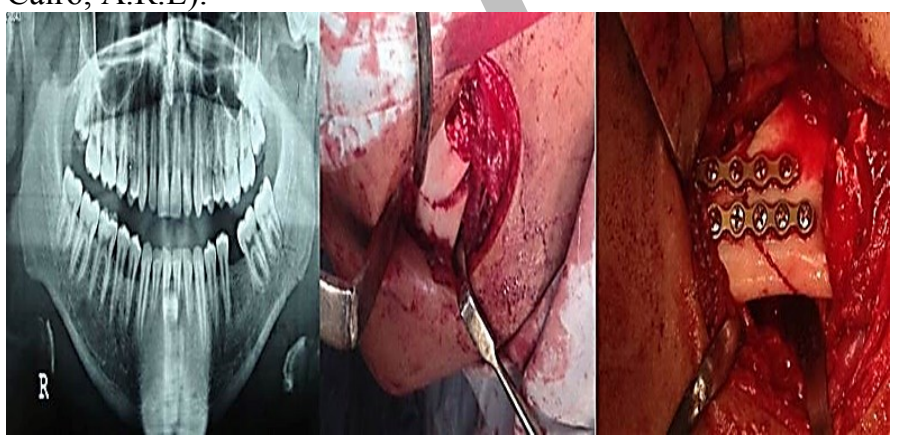

Figure (4): A-Orthopantomogram showing fracture angle, Bexposure of fracture site \& reduction of the segment, C- Two miniplates fixation.

\section{IV.Postoperative Phase \\ 1- Clinical Evaluation}

Clinical evaluation was done the second day, 1 week and 2 weeks postoperatively and at intervals of six weeks and twelve weeks.

Patients were checked for:

- Stability of the fracture segment; fracture side of the mandible were palpated at the lower border to ensure that there is no step deformity and bony crepitus.

- Pain: was measured on visual analogue scale VAS.

\section{2- Radiographic Evaluation}

Orthopantomographic view was taken immediately after operation, six weeks and at twelve weeks.

The radiographic parameters include:

- Proper alignment of bone fragments without displacement.

- The gradual disappearance of the fracture lines which indicates progressive healing of the fracture.

\section{3- Bite force Measurement}

Bite force measurement was conducted after surgical operation weekly for six weeks and at twelve weeks.

\section{Measurement Procedure}

1. The appropriate film range was selected. (ultralow)

2. The film was cut to the precise dimension in the form of horseshoe to measure the bite force. Both sheets donor and receiver sheets were cut to the same exact shape.

3. The 2 rough surfaces were placed together before applying force. By placing these 2 surfaces together, the color forming material on the donor sheet react with the color developing material on the receiver sheet.

4. The film was placed between the upper and lower teeth. Each patient was seated with the head upright and in unsupported natural position. The patient was instructed to bite the sheet as hard as possible for 5 seconds. Instantly and permanently, the film was turned to a magenta color where the intensity was directly proportional to the amount of force being applied. In areas of high force, the fill turned to a dark magenta, while in areas of low force the film magenta tone was lighter. This step was requested in anterior, premolar and molar regions.

\section{Pressure Indicating Film Interpretation}

1. The processed Pressure Indicating Films \& color calibration swatch were scanned

2. Photoshop CS2 (Adobe $\AA$, Photoshop ${ }^{\circledR}$ CS2 version 9, USA) program was used to get the color density on the film and correlate it with the color swatch to determine the amount of pressure applied over the film.

3. The surface area of the exposed points was measured by matching the number of pixels to a known surface area.

4. The force was determined as: Force $=$ Pressure $\times$ Surface area.

\section{STATISTICAL ANALYSIS}

Within each group, values were averaged. In this study, all the data were transferred to SPSS software (SPSS release 16.0, SPSS Chicago I 11).

Descriptive statistics were calculated as mean \pm standard deviation for quantitative variables (age, bite force and percent change in bite force) and frequencies and percentages for qualitative variables (side, site and cause of fracture).

Similarity of the two study groups was investigated by comparing sample characteristics between the two groups 
using $\mathrm{t}$ test for mean age and chi square test for side, site and cause of fracture.

Comparison of mean bite force and percent change between the two study groups for different teeth were done using t test.

Regression analysis was used to study the combined effect of different variables on bite force.

Graphical presentation was done using line graphs for mean bite force of different teeth in different follow up periods.

\section{RESULTS}

The study included 14 patients with mandibular angle fracture in two groups ( 7 patients for the single miniplate and 7 patients for the double miniplates). The average age of all patients ranged from 17 to 29 . Of the total, 12 patients were males and 2 patients were females. Pain \& postoperative complication was found to be similarly occurring in both groups.

\section{Bite force measurements}

The bite force was measured using Pressure Indicating Films. The bite force measurement for group I and group II was conducted following surgical operation weekly for 6 weeks and at 3 months.

The bite force value was calculated and averaged at the anterior region, the premolar region (right \& left) and the molar region (right \& left).

\section{A. Anterior region}

\section{Group I:}

The mean bite force between the anterior teeth was $131.4 \pm 6.68 \mathrm{~N}$ at the first week. There was gradual increase in bite force during the whole follow up period (Table: 1)

\section{Group II:}

The mean bite force between the anterior teeth was $116.69 \pm 5.22 \mathrm{~N}$ at the first week. There was gradual increase in bite force during the follow up period (Table:1)

There was a statistically significant difference between the 2 groups at the $1^{\text {st }}, 2^{\text {nd }}, 3^{\text {rd }}$ and $4^{\text {th }}$ weeks. While there was no statistically significant difference between the 2 groups at the $5^{\text {th }}, 6^{\text {th }}$ and $12^{\text {th }}$ weeks (Table: 1 )

\section{B. Right premolar region \\ Group I:}

The mean bite force between the right premolars was 149.82 $\pm 14.39 \mathrm{~N}$ at the first week. There was gradual increase in bite force during the whole follow up period

(Table: 2).

\section{Group II:}

The mean bite force between the right premolars was 130.29 $\pm 9.89 \mathrm{~N}$ at the first week. There was gradual increase in bite force during the follow up period(Table:2).

There was a statistically significant difference between the 2 groups at the $1^{\text {st }}$ week. While there was no statistically significant difference between the 2 groups at the $2^{\text {nd }}, 3^{\text {rd }}, 4^{\text {th }}$, $5^{\text {th }}, 6^{\text {th }}$ and $12^{\text {th }}$ weeks(Table: 2 )

\section{Left premolar region \\ Group I:}

The mean bite force between the left premolars was 143.88 $\pm 13.34 \mathrm{~N}$ at the first week. There was gradual increase in bite force during the whole follow up period(Table:2)

\section{Group II:}

The mean bite force between the left premolars was 135.74 $\pm 6.49 \mathrm{~N}$ at the first week. There was gradual increase in bite force during the follow up period (Table:2)

There was a statistically significant difference between the 2 groups at the $3^{\text {rd }}$ week. While there were no statistically significant differences between the 2 groups at the $1^{\text {st }}, 2^{\text {nd }}, 4^{\text {th }}, 5^{\text {th }}, 6^{\text {th }}$ and $12^{\text {th }}$ weeks (Table: 2 ).

\section{Right molar region}

\section{Group I:}

The mean bite force between the right molars was $163.27 \pm$ $19.37 \mathrm{~N}$ at the first week. There was gradual increase in bite force during the whole follow up period(Table:3).

\section{Group II:}

The mean bite force between the right molars was $144.03 \pm$ $8.94 \mathrm{~N}$ at the first week. There was gradual increase in bite force during the follow up period(Table:3).

There was a statistically significant difference between the 2 groups at the $5^{\text {th }}, 6^{\text {th }}$ and $12^{\text {th }}$ weeks. While there was no statistically significant difference between the 2 groups at the $1^{\text {st }}, 2^{\text {nd }}, 3^{\text {rd }}$ and $4^{\text {th }}$ weeks(Table: 3 ).

\section{E. Left molar region}

\section{Group I:}

The mean bite force between the left molars was $155.45 \pm$ $18.1 \mathrm{~N}$ at the first week. There was gradual increase in bite force during the whole follow up period(Table:3).

\section{Group II:}

The mean bite force between the left molars was $146.5 \pm$ $6.57 \mathrm{~N}$ at the first week. There was gradual increase in bite force during the follow up period (Table:3).

There was a statistically significant difference between the 2 groups at the $6^{\text {th }}$ and $12^{\text {th }}$ weeks. While there were no statistically significant differences between the 2 groups at the $1^{\text {st }}, 2^{\text {nd }}, 3^{\text {rd }}, 4^{\text {th }}$ and $5^{\text {th }}$ weeks (Table: 3 ).

\section{DISCUSSION}

The use of the non-compression monocortical miniplate fixation for the osteosynthesis of mandibular fractures was advocated by Champy et al. in 1978 and Michelet et al. in 1973 and $(8,12)$. The miniplate system gives sufficient support and stability to bone fragments, allows precise anatomical reduction, and is easy to use (13). Champy et al. in 1978 (8) reported fixation of the angle fractures on the mandibular superior border by means of a non-compression plate to produce a successful outcome. In addition, some in vitro studies suggest that using a second miniplate along the inferior border theoretically creates a second osteosynthesis line and helps stabilize the fixation protecting the fractures against rotation and torsion $(14,15)$.

Maximum occlusal force is a parameter of masticatory function that is relatively easy to measure. In addition, maximum occlusal force is reduced with fractures within the masticatory system $(16,17)$. So, to measure the effectiveness of the miniplates after surgery, estimation of the occlusal force will give a good view of the masticatory function.

Shinogaya et al (18) have evaluated the effects of age on maximum bite force, average magnitudes of pressure, and occlusal contact areas in elderly (53-62 years) and young (20-26 years) Japanese subjects. The occlusal contact areas and maximum bite force were found to be significantly larger in the senior group than in the young group. 
Table 1: Comparison of bite force $(\mathrm{N})$ in anterior region between the two groups during the follow up period.

\begin{tabular}{|c|c|c|c|c|c|c|c|c|c|c|}
\hline & \multicolumn{8}{|c|}{ Group } & \multirow{3}{*}{ P-value } \\
\hline & & \multicolumn{4}{|c|}{ Group I } & \multicolumn{4}{|c|}{ Group II } & \\
\hline & & Mean & SD & Min. & Max. & Mean & SD & Min. & Max. & \\
\hline \multirow{7}{*}{$\begin{array}{c}\text { Premolar } \\
\text { (RT) }\end{array}$} & $1 \mathrm{~W}$ & 149.82 & 14.39 & 129.88 & 163.44 & 130.29 & 9.89 & 112.55 & 143.77 & $0.038^{*}$ \\
\hline & $2 W$ & 159.95 & 16.54 & 134.53 & 174.21 & 155.30 & 4.37 & 147.07 & 160.33 & $0.535 \mathrm{NS}$ \\
\hline & $3 \mathrm{~W}$ & 263.18 & 26.66 & 212.66 & 285.51 & 252.23 & 22.00 & 204.88 & 268.11 & $0.259 \mathrm{NS}$ \\
\hline & $4 \mathrm{~W}$ & 317.98 & 5.85 & 309.51 & 325.07 & 316.70 & 7.08 & 307.11 & 324.13 & $0.710 \mathrm{NS}$ \\
\hline & $5 \mathrm{~W}$ & 329.29 & 7.91 & 317.32 & 339.11 & 336.29 & 7.53 & 327.35 & 346.15 & $0.165 \mathrm{NS}$ \\
\hline & $6 \mathrm{~W}$ & 349.39 & 4.58 & 342.11 & 355.98 & 347.13 & 8.52 & 337.18 & 358.19 & $0710 \mathrm{NS}$ \\
\hline & $12 \mathrm{~W}$ & 362.10 & 6.43 & 351.08 & 369.87 & 356.33 & 8.71 & 346.49 & 369.04 & $0.165 \mathrm{NS}$ \\
\hline \multirow{7}{*}{$\begin{array}{l}\text { Premolar } \\
\text { (LT) }\end{array}$} & $1 \mathrm{~W}$ & 143.88 & 13.34 & 129.13 & 163.03 & 135.74 & 6.49 & 124.88 & 143.08 & $0.383 \mathrm{NS}$ \\
\hline & $2 \mathrm{~W}$ & 153.82 & 13.00 & 137.92 & 174.02 & 155.55 & 3.71 & 148.44 & 158.57 & $0.456 \mathrm{NS}$ \\
\hline & $3 \mathrm{~W}$ & 270.89 & 9.45 & 258.51 & 284.35 & 251.76 & 21.35 & 206.31 & 268.12 & $0.026^{*}$ \\
\hline & $4 \mathrm{~W}$ & 318.09 & 6.22 & 308.89 & 325.03 & 317.02 & 6.87 & 307.95 & 324.08 & $0.805 \mathrm{NS}$ \\
\hline & $5 \mathrm{~W}$ & 329.25 & 6.82 & 319.22 & 338.08 & 336.30 & 7.88 & 326.19 & 345.18 & $0.128 \mathrm{NS}$ \\
\hline & $6 \mathrm{~W}$ & 351.00 & 2.93 & 346.95 & 355.21 & 348.77 & 7.98 & 338.15 & 358.02 & $0.945 \mathrm{NS}$ \\
\hline & $12 \mathrm{~W}$ & 364.82 & 5.43 & 357.89 & 373.05 & 356.80 & 8.84 & 346.22 & 369.05 & $0.097 \mathrm{NS}$ \\
\hline
\end{tabular}

Table 2: Comparison of bite force $(\mathrm{N})$ in premolars region between the two groups during the follow up period.

\begin{tabular}{|c|c|c|c|c|c|c|c|c|c|c|}
\hline & \multicolumn{8}{|c|}{ Group } & \multirow{3}{*}{ P-value } \\
\hline & & \multicolumn{4}{|c|}{ Group I } & \multicolumn{4}{|c|}{ Group II } & \\
\hline & & Mean & SD & Min. & Max. & Mean & SD & Min. & Max. & \\
\hline \multirow{7}{*}{$\begin{array}{c}\text { Molar } \\
\text { (RT) }\end{array}$} & $1 \mathrm{~W}$ & 163.27 & 19.37 & 129.31 & 179.34 & 144.03 & 8.94 & 128.11 & 154.28 & $0.097 \mathrm{NS}$ \\
\hline & $2 \mathrm{~W}$ & 191.63 & 14.64 & 172.08 & 206.13 & 182.14 & 12.28 & 168.12 & 199.51 & $0.165 \mathrm{NS}$ \\
\hline & $3 \mathrm{~W}$ & 306.02 & 6.57 & 296.99 & 312.33 & 295.79 & 10.20 & 279.77 & 304.13 & $0.128 \mathrm{NS}$ \\
\hline & $4 \mathrm{~W}$ & 402.34 & 6.60 & 390.08 & 409.95 & 397.67 & 2.20 & 394.11 & 400.89 & $0.097 \mathrm{NS}$ \\
\hline & $5 \mathrm{~W}$ & 395.65 & 37.86 & 310.15 & 415.03 & 414.15 & 2.85 & 410.34 & 417.59 & $0.038^{*}$ \\
\hline & $6 \mathrm{~W}$ & 438.75 & 6.31 & 426.76 & 445.22 & 427.72 & 5.39 & 420.19 & 437.31 & $0.017^{*}$ \\
\hline & $12 \mathrm{~W}$ & 452.65 & 4.70 & 443.12 & 456.89 & 438.38 & 5.46 & 430.32 & 447.33 & $0.001 *$ \\
\hline \multirow{7}{*}{$\begin{array}{c}\text { Molar } \\
\text { (LT) }\end{array}$} & $1 \mathrm{~W}$ & 155.45 & 18.10 & 131.29 & 179.82 & 146.50 & 6.57 & 134.98 & 153.81 & $0.620 \mathrm{NS}$ \\
\hline & $2 W$ & 186.44 & 14.71 & 171.71 & 205.21 & 184.96 & 13.28 & 165.56 & 199.13 & $0.620 \mathrm{NS}$ \\
\hline & $3 \mathrm{~W}$ & 303.19 & 5.38 & 297.08 & 312.19 & 298.73 & 10.21 & 284.58 & 311.11 & $0.535 \mathrm{NS}$ \\
\hline & $4 \mathrm{~W}$ & 401.47 & 7.74 & 390.88 & 411.82 & 399.49 & 2.46 & 396.58 & 403.87 & $0.318 \mathrm{NS}$ \\
\hline & $5 \mathrm{~W}$ & 411.41 & 4.95 & 402.99 & 418.50 & 413.36 & 2.53 & 408.45 & 416.87 & $0.318 \mathrm{NS}$ \\
\hline & $6 \mathrm{~W}$ & 440.24 & 4.41 & 432.22 & 446.22 & 426.97 & 6.31 & 419.33 & 438.39 & $0.002 *$ \\
\hline & $12 \mathrm{~W}$ & 453.31 & 4.83 & 443.89 & 459.13 & 437.58 & 6.66 & 430.30 & 450.29 & $0.001 *$ \\
\hline
\end{tabular}

Table 3: Comparison of bite force $(\mathrm{N})$ in molars region between the two groups during the follow up period

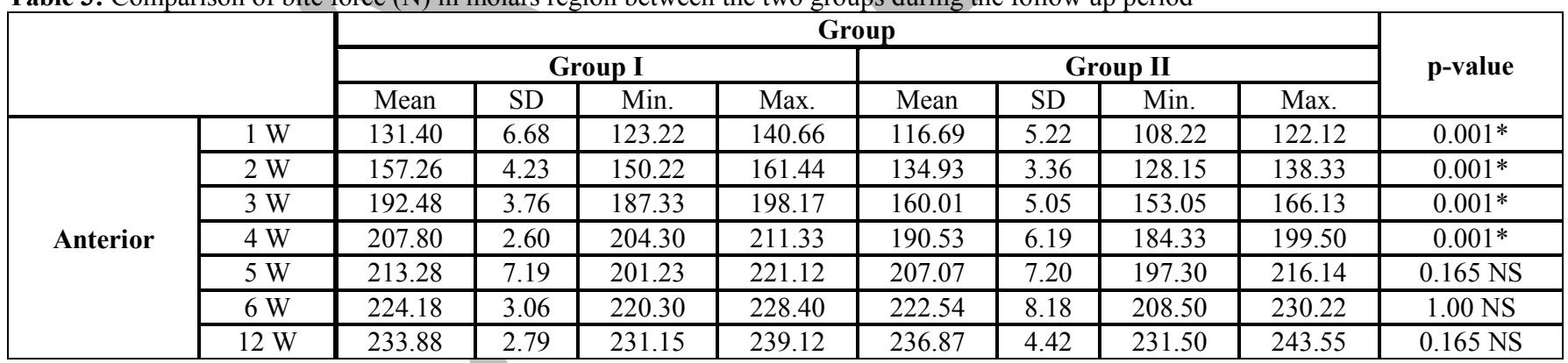

Although the correlation between age and bite force seems to be significant in these studies, it might be assumed that the effect of age on bite force is relatively small (19).

In this study the history of temporomandibular disorders, dentofacial deformities and neurosensory deficiencies were the main exclusion criteria. As such conditions result in significant reduction in the bite force. This was stated by Bonjardim et al in 2005 (20), where they concluded that decreased bite force was correlated with temporomandibular disorders and myofacial pain.

In our study maxillomandibular fixation was done before surgery to adjust occlusion and it was removed directly after the procedure was completed. Smartt et al in 2005(21), stated that MMF has no postoperative role other than maintaining proper occlusion until internal fixation is achieved. In addition,
Bell and Wilson in 2008 (22) concluded that the use of Erich arch bars or interdental wire fixation to assist with MMF during the open reduction and internal fixation of non-comminuted mandibular angle fractures treated in Champy fashion is not always necessary for successful outcome.

Moreover, El-Anwar et al in 2015 (23), reported that many advantages were gained by using intraoral manual occlusion adjustment instead of rigid MMF, including a significant reduction of the operative time and decreased length of general anesthesia. In this study angle fractures were treated by open reduction and internal fixation as it offers early functioning of the mandible, increased patient satisfaction, shorter periods of hospitalization, and earlier return to the workplace. 
The technique for placing a single miniplate at the upper border to fix fractures of the mandibular angle was based on the tension lines of the fracture as proposed by Champy et al. in 1978 and Michelet et al. in $1973(8,12)$

In this study both extraoral and intraoral approaches were used to perform exposure of the fracture. Each approach had its own advantages and disadvantages.

El-Anwar et al. in 2015 (23), mentioned that the intraoral approach performed through an oral mucosal incision, results in minimal external scarring or injury to the marginal mandibular nerve and allows direct visualization and confirmation of the desired occlusion during the placement of the miniplates.

Moreover, Alkan et al in 2007 (24), noticed that when using an intraoral approach, 2-miniplate fixation technique necessitates reflection of all soft tissues from the mandible, increasing intraoperative trauma. Whereas, when using an extraoral approach to place the second miniplate on the inferior border, it increases the risk of bacterial contamination, scarring, postoperative edema, hematoma, and marginal mandibular nerve damage. In addition, 2miniplate fixation prolongs the operation time.

In addition, Gear et al in 2005 (25), showed that the majority of AO (Association for Osteosynthesis) faculty stated that their preferred primary treatment of noncomminuted angle fractures was single miniplates placed on the superior mandibular border through an intraoral approach.

Bite force in this study was measured using pressure sensitive sheets. It is an extremely thin sheet which is able to conform to curved surfaces to evaluate the bite force and occlusal contact area of patients. The readings were taken in five areas - incisor region, the right premolar region, the left premolar region, the right molar region and the left molar region.

Shinogaya et al (18), compared total occlusal load measured with pressure sensitive sheets and conventional unilateral strain-gage transducer (UT). They concluded that a pressure-sensitive film is superior to ordinary measuring systems. This outcome has been explained by two factors. First, bite force can be measured close to intercuspal position, which provides a better opportunity to estimate bite force under natural conditions. Second, the load distribution over the dentition can be studied at the same time $(18,26)$.

The adult human man may generate between 300 and 400 $\mathrm{N}$ maximal bite force (27). This magnitude is reduced when a fracture has occurred in the masticatory system (17). For this reason, when attempting to evaluate the biomechanics of various fixation techniques, it is important to consider clinically relevant parameters to provide meaningful information to the clinician. In the literature, there are only a few investigations that evaluate the bite forces of the postsurgical population $(9,17,28,29)$.

Tate et al. (9) found comparable forces after 1 week $(130 \mathrm{~N})$ and after 6 weeks $(251 \mathrm{~N})$.

Ellis and Walker in 1996 (28), have found that bite forces in the acute postoperative period are much lower than bite forces recorded later in the postoperative period or in the non- operated population. These results agreed with our results in this study. Mastication forces have been shown to decrease dramatically after a fracture, with the values gradually returning to normal as healing progresses.
In addition, based on the studies of bite force in postoperative patients, Haug et al in 2001 (30), postulated that meaningful mechanical behavior would be obtained within the ranges of 0 to $100 \mathrm{~N}$ range for incisal edge loading and 0 to $200 \mathrm{~N}$ for contralateral molar loading, in their biomechanical evaluation of mandibular angle fracture plating techniques with synthetic polyurethane replica mandibles.

This also agreed with Gerlaeh and Schwarz in 2002 (31), who evaluated the maximal biting forces in 22 patients with fractures of angle of mandible treated with miniplate osteosynthesis as per Champy's tension banding principle. They revealed that after 1 week of surgical treatment of fractures, only $31 \%$ of the maximal vertical loading found in controls was registered. These values increased to $58 \%$ at the $6^{\text {th }}$ week postoperatively.

Tate et al in 1994 (9), resulted that the most important reason for the reduced bite force restoration after treatment of fractures of the mandibular angle is traumatic and surgical damage to the masseter and temporalis muscle. Placing fixation hardware from intraoral approach necessitates the masseter muscle and at times a portion of the insertion of the temporalis muscle being stripped from their attachments to the lateral border of the mandible. Another probable reason for reduced bite force restoration in mandibular angle fractures is the presence of protective neuromuscular mechanism in the form of muscle splinting, where selective components of the neuromuscular system are activated or deactivated to take forces off the damaged system.

Raadsheer et al in 1999 (32), stated that the maximum bite force varies with skeletal craniofacial morphology; It decreases with increased vertical facial relationships, the ratio between anterior and posterior facial height, mandibular inclination, and the gonial angle. This is due to the alteration in the facial morphology, directly varying the mechanical advantage of the masseter muscle.

Furthermore, the patient's willingness to bite hard is also a major factor. This is related both to mental attitude and to the comfort of the teeth, so some patients especially within the first postoperative weeks are afraid to use their jaws vigorously (33). This explains the reason for the low values of bite forces recorded in this study at the end of first postoperative week and the considerable large standard deviations between the patients, which were also found in different comparable studies (31).

In this study the highest bite force values were related to the molar region followed by the premolars and finally the least values involved the incisors. This agreed with Ferrario et al in 2004 (16), who resulted that larger forces were found on the molar and premolar teeth, with a symmetric distribution between the left and right side of the arch.

After a steady increase in the bite forces within the first postoperative weeks in our study, we found an unexpected significant decrease in the $5^{\text {th }}$ week related to the right molar region in group $I$.

This result agreed with Tate et al in 1994 (9), who mentioned that one of the possible reasons for this phenomenon is the regeneration of the inferior alveolar nerve and re-innervation of the reflected periosteum with return of pain sensation.

This finding was also in accordance with the findings of the study conducted by Gerlach and Schwarz in 2002 (31), who also found a sharp decline in the bite forces on the $5^{\text {th }}$ 
post-operative week followed again by an increase on the $6^{\text {th }}$ week.

It was also noticed in our study that the increase in the bite force values from the sixth to the twelfth postoperative week was less compared with other intervals.

The bite force values in our study showed no statistically significant differences between the two groups.

This could be related to two main reasons; first, the mechanism of repair and healing of masticatory muscles, as the most important reason affecting the bite force restoration after treatment of fractures of the mandibular angle is traumatic and surgical damage to the masseter and temporalis muscle (9).

Mechanism of healing of masticatory muscles will not change whether one miniplate or two miniplates is used in the management of mandibular angle fracture, as a result the differences in bite force measurements between the two groups was not significant.

Second reason is the correlation between the healing process and the size of the osteotomy gap. Differences in reduction between one miniplate and two miniplates are minimal and mostly will lie in the same gap category resulting in an equal healing process during the follow up periods (34).

\section{CONCLUSIONS}

Within the context of this study, the following conclusions can be listed:

- No significant difference between the uses of either one or two miniplates osteosynthesis in fixation of angle fractures.

- The pressure indicating films had proved to be an easy and fast method to measure the bite force and the distribution of the force on the dental arch.

- The bite force is higher at the molars followed by the premolars and the lowest values at the anterior teeth.

\section{CONFLICT OF INTEREST}

The authors declare that they have no conflicts of interest.

\section{REFERENCES}

1- Natu SS, Pradhan H, Gupta H, Alam S, Gupta S, Pradhan $\mathrm{R}$, et al. An epidemiological study on pattern and incidence of mandibular fractures. Plast Surg Int. 2012; 2012: 834-6.

2- Sojot AJ, Meisami T, Sandor GK, Clokie CM. Epidemiology of Mandibular Fractures Treated at the Toronto General Hospital: A Review of 246 Cases. J Can Dent Assoc. 2001; 67: 640-4.

3- Deogratius BK, Isaac MM, Farrid S. Epidemiology and management of maxillofacial fractures treated at Muhimbili National Hospital in Dar es Salaam, Tanzania, 1998-2003; Int Dent J. 2006; 56: 131-4.

4- Sirimaharaj W, Pyungtanasup K. The Epidemiology of Mandibular Fractures Treated at Chiang Mai University Hospital: A Review of 198 Cases. J Med Assoc Thai. 2008; 91: 868-74.

5- Barrera JE, Meyers AD. Mandibular Body Fractures Treatment \& Management. available from: http://emedicine.medscape.com/article/869123-treatment

6- Albert J, Fox MD, Robert M, Kellman MD. Mandibular angle fractures (two miniplate fixation and complications). Arch Facial Plast Surg. 2003; 5: 464-9.
7- Levy F, Smith R, Odland R, Marentette L. Monocortical miniplate fixation of mandibular angle fractures. Arch Otolaryngol Head Neck Surg. 1991; 117: 149-54.

8- Champy M, Lodde JP, Schmitt R, Jaeger JM, Muster D. Mandibular osteosynthesis by miniature screwed plates via a buccal approach. J Maxillofac Surg. 1978; 6: 14-21.

9- Tate GS, Ellis E III, Throckmorton G. Bite forces in patients treated for mandibular angle fractures: implications for fixation recommendations. J Oral Maxillofac Surg. 1994; 52: 734-6.

10-Kumar ST, Saraf S, Devi SP (2013) Evaluation of bite force after open reduction and internal fixation using microplates. J Dent 10(5):466-77

11-Sybil D, Gopalkrishnan K. Assessment of Masticatory Function Using Bite Force Measurements in Patients Treated for Mandibular Fractures. Craniomaxillofacial Trauma \& Reconstruction. 2013;6(4):247-50. doi:10.1055/s-0033-1356755.

12-Michelet FX, Deymes J, Dessus B. Osteosynthesis with miniaturized screwed plates in maxillofacial surgery. J Maxillofac Surg. 1973; 1: 79-84.

13-Kuriakose MA, Fardy M, Sirikumara M, Patton DW, Sugar AW. A comparative review of 266 mandibular fractures with internal fixation using rigid (AO/ASIF) plates or miniplates. Br J Oral Maxillofac Surg. 1996; 34: 315-21.

14-Siddiqui A, Markose G, Moos KF, McMahon J, Ayoub AF. One miniplate versus two in the management of mandibular angle fractures: a prospective randomised study. Br J Oral Maxillofac Surg. 2007; 45: 223-5.

15-Adeyemo WL, Iwegbu IO, Bello SA, Okoturo E, Olaitan AA, Ladeinde AL, et al. Management of mandibular fractures in a developing country: a review of 314 cases from two urban centers in Nigeria. World J Surg. 2008; 32: 2631-5.

16-Ferrario VF, Sforza C, Serrao G, Dellavia C, Tartaglia GM. Single tooth bite forces in healthy young adults. J Oral Rehabil. 2004; 31: 18-22.

17-Ellis E III, Throckmorton GS. Bite forces after open or closed treatment of mandibular condylar process fractures. J Oral Maxillofac Surg. 2001; 59: 389-95.

18-Shinogaya T, Bakke M, Thomsen CE, Vilmann A, Matsumoto M. Bite force and occlusal load in healthy young subjects--a methodological study. Eur J Prosthodont Restor Dent. 2000; 8: 11-5

19-Van Der Bilt A, Tekamp FA, Van Der Glas HW, Abbink JH. Bite force and electromyograpy during maximum unilateral and bilateral clenching. Eur J Oral Sci. 2008; 116 : 217-22.

20-Bonjardim LR, Gavião MB, Pereira LJ, Castelo PM. Bite force determination in adolescents with and without temporomandibular dysfunction J Oral Rehabil. 2005; 32: 577-83.

21-Smartt JM Jr, Low DW, Bartlett SP. The pediatric mandible: II. Management of traumatic injury or fracture. Plast Reconstr Surg. 2005; 116: 28e-41e.

22-Bell RB, Wilson DM. Is the use of arch bars or interdental wire fixation necessary for successful outcomes in the open reduction and internal fixation of mandibular angle fractures? J Oral Maxillofac Surg. 2008; 66: 2116-22.

23-El-Anwar MW, Sayed El-Ahl MA, Amer HS. Open reduction and internal fixation of mandibular fracture without rigid maxillomandibular fixation. Int Arch Otorhinolaryngol. 2015; 4: $314-8$. 
24-Alkan A, Metin M, Muglali M, Ozden B, Celebi N. Biomechanical comparison of plating techniques for fractures of the mandibular condyle. Br J Oral Maxillofac Surg. 2007; 45:145-9.

25-Gear AJ, Apasova E, Schmitz JP, Schubert W. Treatment modalities for mandibular angle fractures. J Oral Maxillofac Surg. 2005; 63: 655-63.

26-Shinogaya T, Bakke M, Thomsen CE, Vilmann A, Sodeyama A, Matsumoto M. Effects of ethnicity, gender and age on clenching force and load distribution. Clin Oral Investig. 2001; 5: 63-8.

27-Fedok FG, Van Kooten DW, DeJoseph LM, McGinn JD, Sobota B, Levin RJ, et al. Plating techniques and plate orientation in repair of mandibular angle fractures: an in vitro study. Laryngoscope. 1998; 108: 1218-24.

28-Ellis E $3^{\text {rd }}$, Walker LR. Treatment of mandibular angle fractures using one noncompression miniplate. J Oral Maxillofac Surg. 1996; 54: 864-71.

29-Throckmorton GS, Bushang PH, Ellis E. Improvement of maximum occlusal forces after orthognathic surgery. J Oral Maxillofac Surg. 1996; 54: 1080-6.

30-Haug R, Fattahi T, Goltz MA. Biomechanical evaluation of mandibular angle fracture plating techniques. J Oral Maxillofac Surg. 2001; 59: 1199-210.

31-Gerlach KL, Schwarz A. Bite forces in patients after treatment of mandibular angle fractures with miniplate osteosynthesis according to Champy. Int J Oral Maxillofac Surg. 2002; 31: 345-8.

32-Raadsheer MC, van Eijden TM, van Ginkel FC, PrahlAndersen B. Contribution of jaw muscle size and craniofacial morphology to human bite force magnitude. J Dent Res. 1999; 78: 31-42.

33-Bhatnagar A, Bansal V, Kumar S, Mowar A. Comparative analysis of osteosynthesis of mandibular anterior fractures following open reduction using stainless steel lag screws and mini plates. J Maxillofac Oral Surg. 2013; 12: 133-9.

34-Claes L, Eckert-Hübner K, Augat P. The fracture gap size influences the local vascularization and tissue differentiation in callus healing. Langenbecks Arch Surg. 2003; 388: 316-22 